\title{
Human-Induced Disturbance Alters Pollinator Communities in Tropical Mountain Forests
}

\author{
Stephan Kambach ${ }^{1}{ }^{*}$, Fernando Guerra ${ }^{2}$, Stephan G. Beck ${ }^{3}$, Isabell Hensen ${ }^{1}$ and \\ Matthias Schleuning ${ }^{1,4, *}$
}

1 Institute of Biology/Geobotany and Botanical Garden, Martin-Luther-University Halle-Wittenberg, Am Kirchtor 1, 06108 Halle, Germany; E-Mail: isabell.hensen@botanik.uni-halle.de

2 Estación Biológica Tunquini, Instituto de Ecología, Universidad Mayor de San Andrés, Casilla 10077, Correo Central. La Paz, Bolivia; E-Mail: ferguerrafideo@yahoo.com

3 Herbario Nacional de Bolivia, Universidad Mayor de San Andrés, Cota Cota, La Paz 10077, Bolivia; E-Mail: lpbstephanbeck@yahoo.com

4 Biodiversity and Climate Research Centre (BiK-F) and Senckenberg Gesellschaft für Naturforschung, 60325 Frankfurt am Main, Germany

* Author to whom correspondence should be addressed; E-Mails: Stephan.Kambach@gmx.de (S.K.); Matthias.Schleuning@senckenberg.de (M.S.); Tel.: +49-152-385-681-51.

Received: 13 November 2012; in revised form: 29 November 2012 / Accepted: 14 December 2012 / Published: 27 December 2012

Abstract: Mountain forest ecosystems in the Andes are threatened by deforestation. Increasing fire frequencies lead to fire-degraded habitats that are often characterized by a persistent fern-dominated vegetation. Little is known about the consequences of these drastic changes in habitat conditions for pollinator communities. In a rapid diversity assessment, we collected individuals of two major groups of insect pollinators (bees and butterflies/moths) with pan traps and compared pollinator diversities in a spatial block design between forest interior, forest edge and adjacent fire-degraded habitats at eight sites in the Bolivian Andes. We found that bee species richness and abundance were significantly higher in fire-degraded habitats than in forest habitats, whereas species richness and abundance of butterflies/moths increased towards the forests interior. Species turnover between forest and fire-degraded habitats was very high for both pollinator groups and was reflected by an increase in the body size of bee species and a decrease in the body size of butterfly/moth species in fire-degraded habitats. We conclude that deforestation by frequent fires has profound impacts on the diversity and composition of pollinator communities. Our tentative findings suggest shifts towards bee-dominated pollinator 
communities in fire-degraded habitats that may have important feedbacks on the regenerating communities of insect-pollinated plant species.

Keywords: Anthropogenic fires; Apiformes; biodiversity; body size; Bolivian Andes; human disturbance; insect pollinators; Lepidoptera; rain forest; species traits

\section{Introduction}

The tropical Andes are one of the global hotspots of plant and animal diversity [1,2]. In addition to the impacts of logging and land-use changes, Andean montane forest ecosystems are severely threatened by fire incidents, often caused by uncontrolled slash-and-burn agriculture. A predicted future increase in El Niño-related droughts is likely to exacerbate the impacts of fire on forest ecosystems in the tropical Andes [3]. Deforestation and forest fragmentation even increase the susceptibility of forest remnants to fires [3]. In many parts of the tropical Andes, these fire-cleared areas, which have been abandoned for 10-20 years, are nowadays widely dominated by a dense cover of bracken fern, Pteridium aquilinum var. arachnoideum (Kaulf.) Brade. Because of their strong competitive capability and further spread in case of repeated fire events, these fire-degraded ecosystems are long-lasting and may even mark a final succession stage [4-6].

Animal-mediated ecosystem processes, such as pollination and seed dispersal, are crucial for forest restoration [7]. This is particularly true in the tropics where most woody plant species depend on animal vectors for pollination and seed dispersal [8,9]. Consequently, plant reproductive success is often pollen-limited in the tropics, largely due to inadequate pollinator visitation [10]. It is consensus that pollinator communities and plant-pollinator interactions are susceptible to human-induced habitat disturbances [11-13]. However, effects of forest disturbance on bee and butterfly species diversity can be scale dependent $[14,15]$ and the extent to which pollinators are able to move between different habitat types is contentious [16]. Factors driving the responses of pollinator assemblages to humaninduced habitat disturbance can be changes in flower compositions [17,18] but also changes in environmental conditions both at the local and at the landscape scale [19].

One important environmental factor influencing animal pollinators is temperature because it strongly influences the individual activities and thus the local habitat preferences of animal pollinators [20]. Changes in habitat conditions may not only change community composition, but also the small-scale distribution of species traits. For instance, pollinator body size dictates the warm up rate [21] and the temperatures necessary for initiating flight [20] and might also play a role in predatorprey interactions [22]. Previous studies have therefore suggested that body size is also associated with the species ability to resist habitat loss [23]. As a consequence, human-induced habitat disturbance is likely to favor different life-history strategies and pollinator morphologies [23].

The re-establishment of pollinator communities during succession as well as the importance of plant-pollinator interactions for forest management are still highly unexplored [11]. We therefore asked how pollinator communities respond to a human-induced disturbance gradient in tropical montane forests. The answer to this question may have important implications for forest restoration in the tropical Andes because responses of insect pollinator communities to human-induced habitat 
gradients can have crucial feedbacks on the regeneration processes of insect-pollinated plant species in degraded habitats [24,25]. We employed a steep habitat gradient from forest interior over forest edge to fire-degraded habitats dominated by a vegetation of pioneer shrubs and ferns. In a spatial block design, we compared the diversity of two important guilds of animal pollinators (1) Apiformes (bees) and (2) Lepidoptera (butterflies and moths) among habitat types. We addressed the following questions:

(1) Do pollinator richness and abundance of bee and butterfly/moth pollinator guilds decrease from the forest interior towards fire-degraded habitats?

(2) Does the community composition of both pollinator guilds change between forest and fire-degraded habitats?

(3) Do changes in habitat conditions cause changes in the body size of the pollinator guilds?

\section{Methods}

\subsection{Site Description}

Study sites were located on the eastern slopes of the Andes near the city of Chulumani, Bolivia $\left(16^{\circ} 24^{\prime} 29^{\prime \prime} \mathrm{S}, 67^{\circ} 31^{\prime} 15^{\prime \prime} \mathrm{W} ; 1.750 \mathrm{~m}\right.$ a.s.1.). The mean annual temperature is $20.8^{\circ} \mathrm{C}$ [26]. Mean annual precipitation is $1.366 \mathrm{~mm}$ and can be restricted to less than $50 \mathrm{~mm}$ per month during the dry season from May to July [26].

Two remnants of primary forests, Reserva Ecológica Apa-Apa and Bosque de Cala Cala, were investigated in this study (Figure 1). In each forest remnant, four sites were set up at the forest borders. Selection criteria for these sites were: (i) The fire-degraded sites were located adjacent to a forest fragment. (ii) The adjacent parts of these forests covered more than $600 \mathrm{~m}$ in diameter. (iii) The homogeneous fire-cleared site covered more than $150 \mathrm{~m}$ in diameter. All investigated sites were situated at 1940-2500 $\mathrm{m}$ a.s.1.

Figure 1. Map of the study area in the Bolivian Andes. Forest remnants are shown in green, the eight study sites at the forest borders are marked by red points.

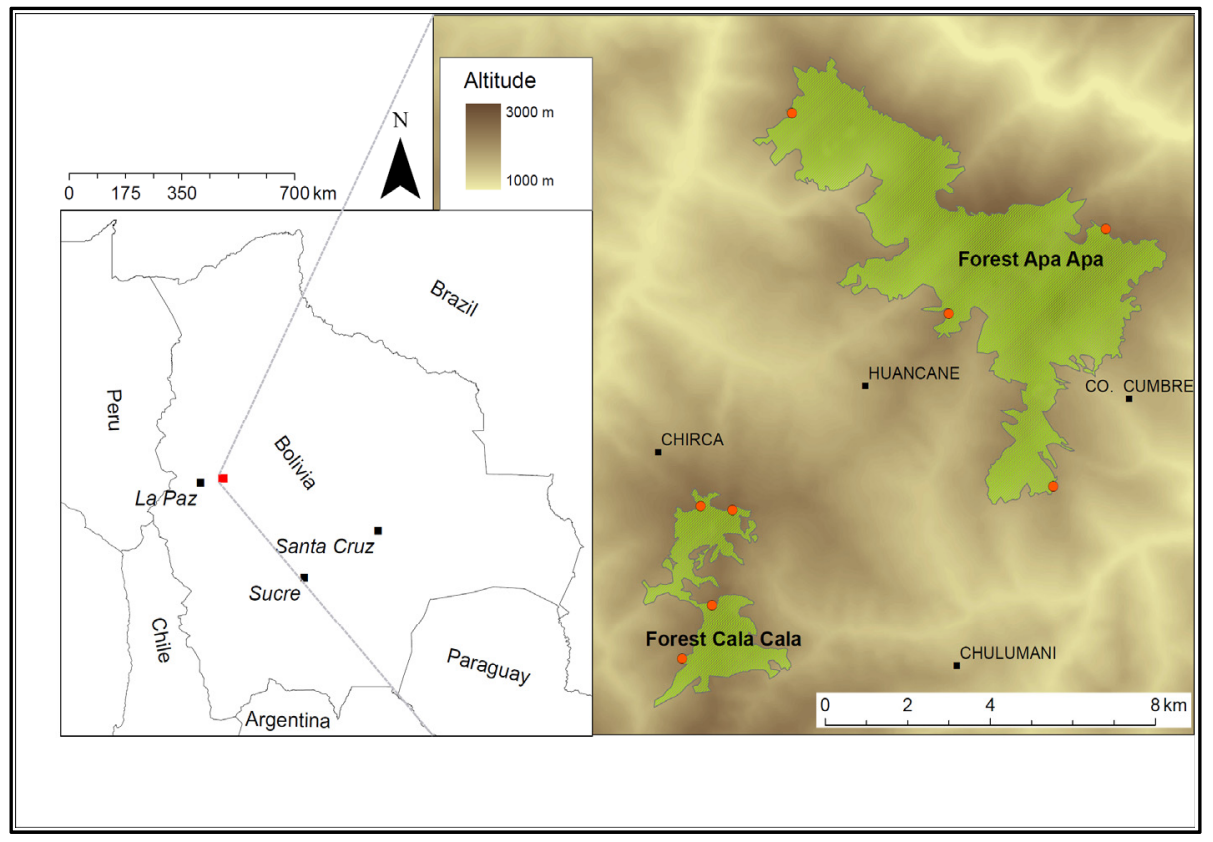


At each site, we established one spatial block alongside a previously established transect, perpendicular to the forest border. Each spatial block comprised three habitat types: (1) Forest interior, situated $120 \mathrm{~m}$ distant from the forest border, (2) Forest edge, situated at the border between forest and fire-degraded habitat, and (3) Fire-degraded area, $120 \mathrm{~m}$ distant from the forest border. At a single site, the fire-degraded habitat could not be sampled because it burned down during the time of the study.

In contrast to forest habitats, the fire-degraded and now fern-dominated habitats lack any trees higher than $5 \mathrm{~m}$, but comprise patches of insect-pollinated pioneer shrubs, e.g., Borreria capitata (Ruiz \& Pev.) DC. (Rubiaceae), Collaea speciosa (Loisel.) DC. (Fabaceae) or Raulinoreitzia crenulata (Spreng.) R.M. King \& H. Rob. (Asteraceae). Abiotic conditions show higher fluctuations during the course of a day in fire-degraded habitats than in forest habitats, with particularly high temperatures and arid conditions during times of sun exposure (D. Lippok and S. Gallegos Ayala, unpublished data).

\subsection{Sampling}

The study took place from February to May 2011. Bee and butterfly/moth individuals were caught with pan traps $[27,28]$. Although they may differ in their attraction among different bee species, pan traps are a frequently used, standardized passive sampling technique [27,28], often used in biodiversity assessments $[19,29]$. In order to attract a wide spectrum of potential pollinators $[28,30]$, commercially available white plastic dishes were additionally painted in yellow and blue. These traps were filled with $300 \mathrm{~mL}$ of water and a dash of odorless soluble. Three pan traps, one of each color (white, yellow, blue), were placed in breast height. Thus, our study design compares pollinator diversity in the lower vegetation strata. In every habitat type at each site, three pan trap bundles were installed in a distance of 10 meters from each other.

First, bee species were collected for $24 \mathrm{~h}$ at every site. In a second sampling, bee and butterfly/moth species were collected for $48 \mathrm{~h}$ at every site. At a single study site, individuals were accidentally collected for five days instead of two days. Assuming a linear relationship between time and number of caught individuals, we applied a rarefaction approach to create a randomly rarefied community sample that was used in further analyses for this particular site. All collected specimen were stored in $60 \%$ ethanol and later identified to morphospecies at the Universidad Mayor de San Andrés, La Paz/Bolivia. For each morphospecies, we also measured its body length (i.e., distance from caput to abdomen) as a measure of body size.

We acknowledge that the sampling effort at each site was too low for estimating the true species richness in these diverse tropical pollinator communities. However, the aim of this rapid diversity assessment was to compare relative differences in pollinator diversity among the three habitat types. Because sampling effort and design were highly standardized in all habitat types, potential differences in species richness and community composition among habitat types are very unlikely to arise from sampling bias and are instead indicative of changes in the respective pollinator communities.

\subsection{Statistical Analysis}

All statistical analyses were conducted with R, version 2.14.0 [31] and dedicated packages: vegan [32], nlme [33] and ade4 [34]. 
For each habitat type and study site, we determined the cumulative species richness and species abundance across all samplings and compiled a community matrix including species abundances, i.e., the cumulative individual number per morphospecies. Species richness and abundance were squareroot transformed to meet normality assumptions. Bee and butterfly/moth richness and abundance were compared between different habitat types, using linear mixed-effect models with habitat as predictor variable and site as random factor to account for the spatial block design of sampling. We defined two orthogonal contrasts in order to identify differences in potential pollinator richness and abundance between (i) forest habitats (interior and edge) and fire-degraded habitats, and between (ii) forest interior and forest edge. Significances of both contrasts were tested using t-statistics.

Because shifts in community composition from habitat loss may be masked when only species richness is measured [35], changes in species composition were analyzed with a detrended correspondence analysis (DCA), based on the quantitative community matrix. The influence of rare species was down-weighted and a single outlying community from a fire-degraded habitat had to be excluded from the ordination analysis. We tested whether species compositions correlated with (i) habitat identity and (ii) altitude of the study sites. We also calculated the proportions of bee and butterfly/moth species in pollinator communities for each habitat type and study site and related their proportions to the gradient in species turn-over. Significances of predictor variables on community composition were tested with a permutation test (1,000 permutations). Effects of habitat type were tested with a stratified randomization approach within sites.

In order to test for differences in body sizes of bee and butterfly/moth guilds among habitats, we applied fourth-corner analyses to detect significant associations between species traits and habitat characteristics [36,37]. For both potential pollinator guilds, we compared body sizes with two approaches. First, we compared body sizes within each pollinator guild; bee body sizes had to be logtransformed. Second, we assigned species to be 'large' or 'small', separated by the median in body size in each guild (median for bees: $6.5 \mathrm{~mm}$; median for butterflies/moths: $14.5 \mathrm{~mm}$ ). By contrasting small and large size classes, we were able to test whether changes in body sizes were driven by responses of the small- or the large-bodied pollinators. In order to test for significances in correlations between species traits and environment, Legendre et al. [36] proposed four permutation models. According to our study questions, we applied model 1 and 2 . In model 1 , values for each species are permuted independently, assuming that individual species respond to the habitat gradient. In model 2, entire rows are permuted, assuming that fixed assemblages of species prefer environmentally distinct habitats. We conducted permutation tests using model 1 and model 2 with 999 permutations. Since $p$-values from both permutation models were qualitatively identical, we only report $\mathrm{p}$-values from permutation model 1 .

\section{Results}

In total, 356 bee individuals, belonging to 67 morphospecies, and 303 Lepidoptera individuals, belonging to 124 morphospecies, were collected. A full list of collected individuals per morphospecies, habitat type and study site is provided in the Supplement. Notably, we recorded 32 individuals of the introduced honeybee Apis mellifera L., none of them in forest interior. 
Bee richness and abundances were higher in fire-degraded habitats than in the adjacent forests. In contrast to bee diversity, butterfly/moth richness and abundances were higher in forest habitats than in adjacent fire-degraded habitats and were significantly higher in forest interior than at forest edges (Figure 2, Table 1).

Figure 2. Species richness and abundance of two pollinators guilds collected with pan traps in three different habitat types in the Bolivian Andes. Bee species richness and abundance are shown in (a) and (b), butterfly/moth species richness and abundance in (c) and (d). Habitat types were: (i) fire-degraded, (ii) forest edge and (iii) forest interior habitats.
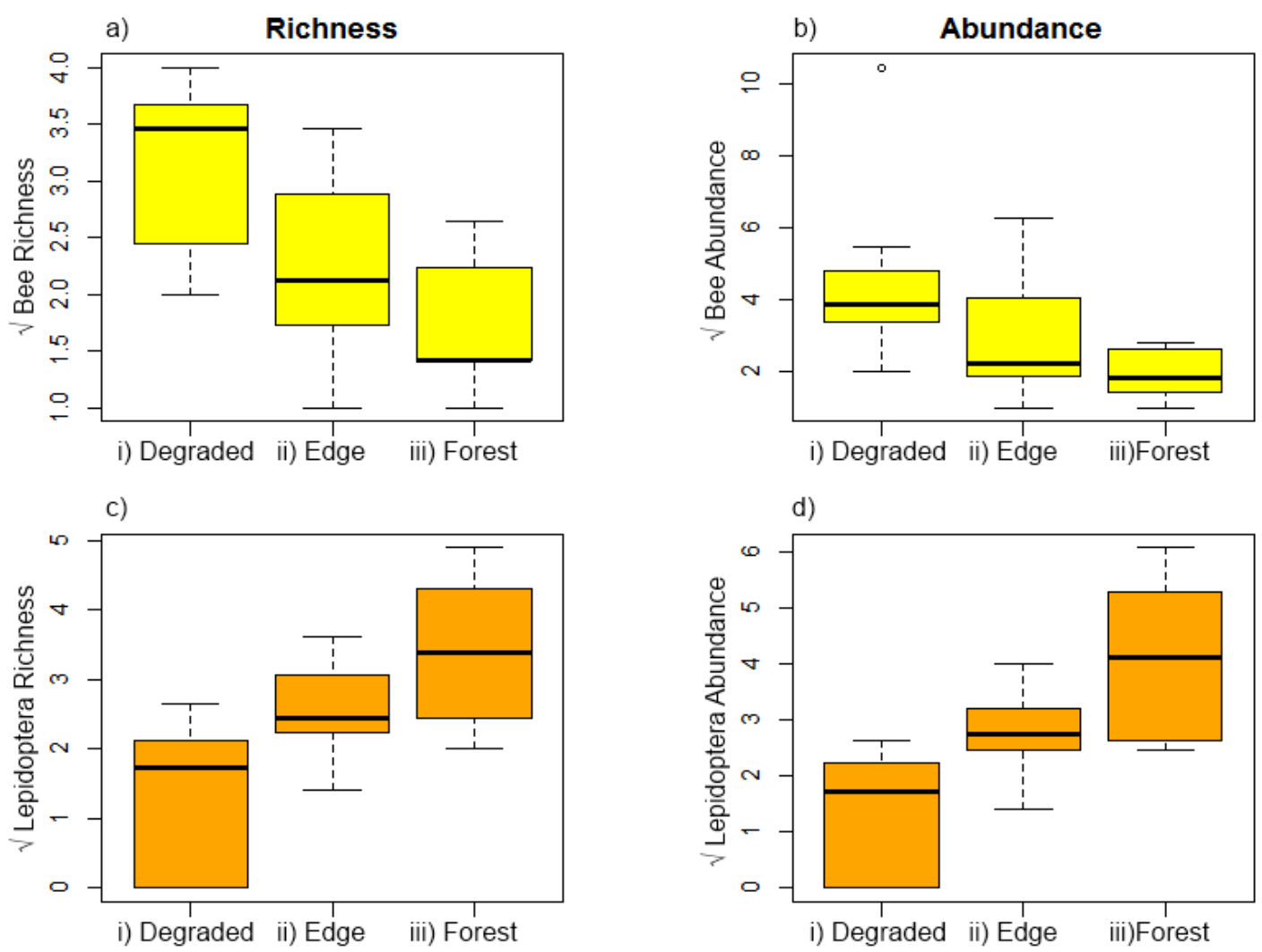

Species richness and abundance were square-root transformed prior to analysis. Horizontal lines across boxes are medians, boxes indicate 25th and 75th percentiles, whiskers indicate the data range, and circles are outliers. Statistical differences are provided in Table 1.

Community turn-over from forest interior to fire-degraded habitats was high, indicating a complete species turnover (axis lengths: first axis 5.3 standard deviations, second axis 3.9 standard deviations). Ordination axes explained $37.2 \%$ and $26.9 \%$ of community turnover, respectively. Forest interior and fire-degraded habitats were clearly separated in the ordination plot, while forest edges were characterized by transitional species communities (Figure 3$)$. Habitat types explained $40 \%\left(\mathrm{r}^{2}=0.40\right.$; $p<0.001)$ of the variation in species turn-over and thus slightly more than the species turn-over along the elevation gradient $\left(36 \% ; \mathrm{r}^{2}=0.36 ; p=0.01\right)$. Consistent with the observed changes in species richness and abundance, bee species dominated the fire-degraded habitats $\left(\mathrm{r}^{2}=0.75 ; p<0.001\right)$, whereas butterfly/moth species increased in relative abundance in forest interiors $\left(\mathrm{r}^{2}=0.69 ; p=0.002\right)$. 
Table 1. Differences in species richness and abundance of two pollinator guilds (bees and butterflies/moths) between three habitat types at eight study sites in the Bolivian Andes. Habitat types were: (i) fire-degraded, (ii) forest edge and (iii) forest interior habitats. Results are from linear mixed-effect models including site as random factor. We applied two orthogonal contrasts to test differences between (i) forest (including interior and edge) $v s$. fire-degraded habitats and (ii) forest interior $v s$. forest edge.

\begin{tabular}{llccccc}
\hline Bees & & Estimate & Std. Error & DF & t-value & $\boldsymbol{p}$-value \\
\hline Richness & Forest $v s$. degraded & -0.53 & 0.13 & 13 & -3.80 & $\mathbf{0 . 0 0 2}$ \\
& Interior $v s$. edge & -0.25 & 0.15 & 13 & -1.70 & 0.112 \\
\multirow{2}{*}{ Abundance } & Forest $v$ s. degraded & -1.07 & 0.37 & 13 & -2.83 & $\mathbf{0 . 0 1 4}$ \\
& Interior $v$ s. edge & -0.49 & 0.41 & 13 & -1.20 & 0.251 \\
\hline Lepidoptera & & & & & & \\
\hline \multirow{2}{*}{ Richness } & Forest $v s$. degraded & 0.88 & 0.14 & 13 & 6.05 & $<\mathbf{0 . 0 0 1}$ \\
& Interior $v s$. edge & 0.41 & 0.15 & 13 & 2.64 & $\mathbf{0 . 0 2 0}$ \\
Abundance & Forest $v s$. degraded & 0.17 & 0.17 & 13 & 6.31 & $<\mathbf{0 . 0 0 1}$ \\
& Interior $v s$. edge & 0.64 & 0.18 & 13 & 3.51 & $\mathbf{0 . 0 0 4}$ \\
\hline
\end{tabular}

Figure 3. Result of a detrended correspondence analysis testing for species turn-over in pollinator communities of two pollinator guilds (bees, butterflies/moths) along habitat gradients comprising forest interior, forest edge and fire-degraded habitats in the Bolivian Andes. Effects of habitat type, altitude and of the proportion of pollinator guilds on community composition are indicated by the respective centroids or vectors; all effects shown were significant $(p<0.05$ in a permutation test).

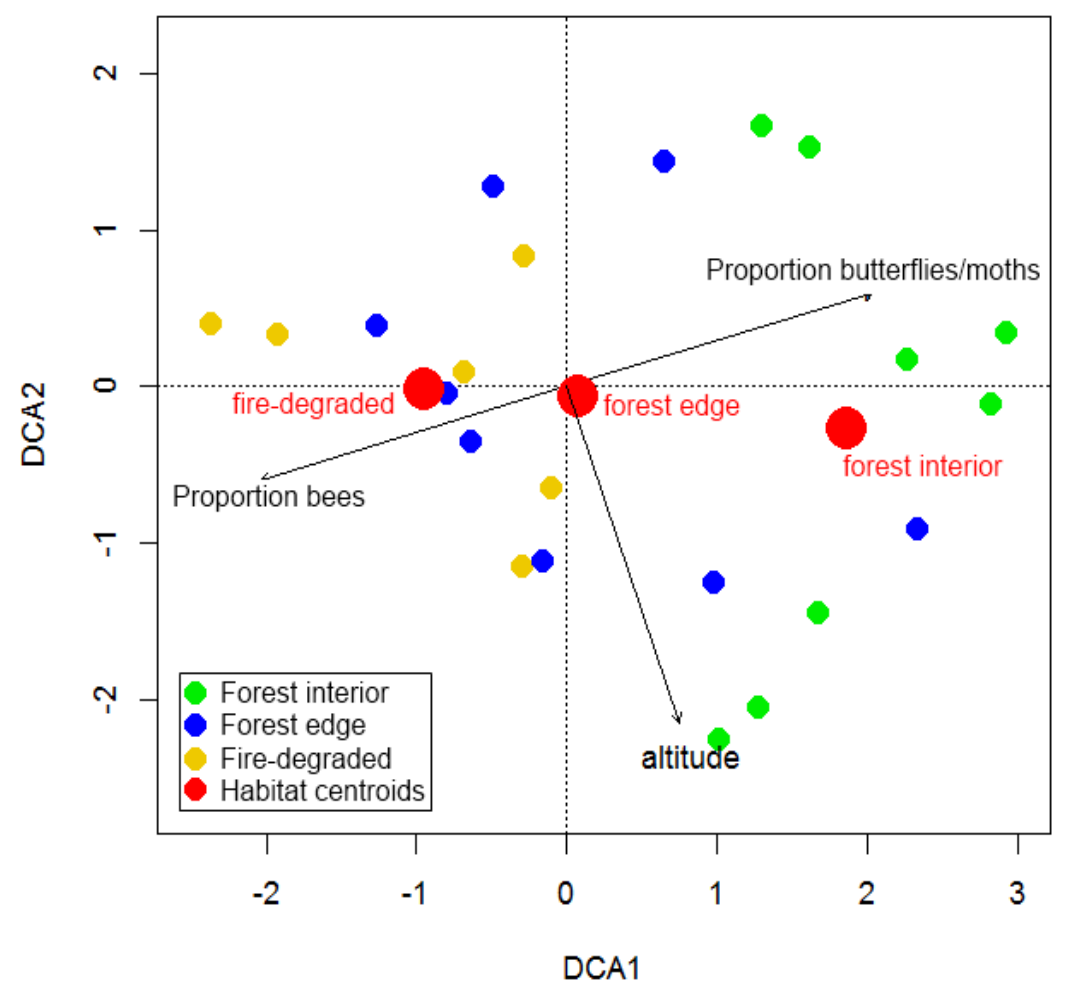


Body sizes of bee and butterfly/moth communities changed along the habitat gradient (Table 2). Body sizes of bee species decreased in the forest interior, whereas body sizes of butterfly/moth communities decreased in fire-degraded habitats. In both pollinator guilds, these changes were driven by the response of large-bodied species to the habitat gradient (Table 2). After excluding the introduced honeybee $A$. mellifera from the analysis, the abundance of large-bodied pollinators was still reduced in the forest interior $\left(\mathrm{X}^{2}=3.29, p=0.007\right)$.

Table 2. Fourth-corner analyses of body sizes of two pollinator guilds (bees and butterflies/moths) along a human-induced habitat gradient comprising forest interior, forest edge and fire-degraded habitats. Non-random distribution of body sizes was tested using Fand $\chi^{2}$-statistics in permutation model 1 [35]. Holm's corrected $p$-values are provided; significant $p$-values $(p<0.05)$ are printed in bold. Effect sizes that indicate an increase or decrease of body size in the respective habitat type are indicated by "+" and "-", respectively.

\begin{tabular}{lllll|lll}
\hline & \multicolumn{4}{c}{ Bees } & \multicolumn{3}{c}{ Lepidoptera } \\
\cline { 2 - 8 } & Size $(\mathrm{F})$ & Small $\left(\chi^{2}\right)$ & Large $\left(\chi^{2}\right)$ & Size $(\mathrm{F})$ & \multicolumn{2}{c}{ Small $\left(\chi^{2}\right)$} & Large $\left(\chi^{2}\right)$ \\
\hline Fire-degraded & 0.1 & 8.6 & $\mathbf{1 1 . 4}+$ & $\mathbf{0 . 3}$ & - & 5.5 & $\mathbf{4 . 1}-$ \\
$p$-Value & 0.187 & 0.720 & $\mathbf{0 . 0 1 5}$ & $\mathbf{0 . 0 0 3}$ & 0.132 & $\mathbf{0 . 0 0 6}$ \\
\hline Forest edge & 0.1 & 8.4 & 9.2 & 0.0 & 10.2 & 11.3 \\
$p$-Value & 0.178 & 0.720 & 0.720 & 0.399 & 0.452 & 0.489 \\
\hline Forest interior & $\mathbf{0 . 2}-$ & 11.1 & $\mathbf{3 . 4}-$ & $\mathbf{0 . 2}+$ & 10.6 & $\mathbf{1 7 . 4}+$ \\
$p$-Value & $\mathbf{0 . 0 2 4}$ & 0.720 & $\mathbf{0 . 0 0 6}$ & $\mathbf{0 . 0 1 6}$ & 0.435 & $\mathbf{0 . 0 0 6}$ \\
\hline
\end{tabular}

\section{Discussion}

\subsection{Species Richness and Abundance}

Species richness of bees and butterfly/moth communities changed along the human-induced habitat gradient. Notably, both pollinator guilds were differently affected by altered habitat conditions. The high structural diversity at the contact zone between fire-degraded and forest habitats did not lead to an increase in species richness, neither in bee nor in butterfly/moth communities. Bee species richness was highest in fire-degraded habitats, whereas butterfly/moth richness significantly decreased in fire-degraded, now fern-dominated habitats. For bee species, Oteri and Sandino [38] also reported a higher abundance of bees in open farmland habitats than in tropical forests but, different from our study, forests still accounted for highest species richness. Contrarily, Liow et al. [39] described lower species richness but higher abundance in primary forests when compared to disturbed forest ecosystems. Diversity and abundance of Euglossine bees were reported to be unaffected by habitat alterations [40]. Thus, responses of bee pollinators to human-induced habitat disturbance appear to be context-dependent and may strongly depend on the type of habitat modification [29] and the surrounding landscape matrix [29].

In our study, we collected 32 individuals of the invasive honeybee [41], Apis mellifera L., in fire-degraded habitats and at forest edges. Honeybees contributed strongly to the increase in bee species richness in disturbed habitats and were strictly bound to disturbed habitats, a phenomenon also 
found in other studies $[42,43]$. Further research on the question whether honeybees indeed provide pollination functions and connect forest edges with the surrounding habitat matrix or whether they compete with native pollinators for resources [44] are crucial for assessing the potential value of honeybees for forest restoration.

The observed decline in butterfly/moth species diversity in fire-degraded habitats is consistent with previous studies $[13,45,46]$. Apart from climate and topography, human disturbance was reported to be one of the most important determinants of butterfly diversity [40]. In most studies, species diversity of Lepidoptera was negatively associated with the intensity of human disturbance $[13,45,46]$, leading to reductions in butterfly richness and abundance of up to $80 \%$ in a temperate system [47]. On a larger scale, however, small-scale forest disturbances could even increase Lepidoptera richness [48].

We acknowledge that not only spatial, but also temporal variations in biotic and abiotic conditions influence species diversity [48,49]. Repeated samplings in different seasons could give a more comprehensive insight into differences in species diversity between forest and fire-degraded habitats in our study system. For instance, tropical Hymenoptera exhibited higher temporal species turnover in forest habitats compared to disturbed agricultural ecosystems [50].

\subsection{Species Turn-Over}

At a small spatial scale of $240 \mathrm{~m}$, our study revealed a complete species turnover between forest understorey and fire-degraded habitats. This demonstrates that bee and butterfly/moth species, albeit long distance foragers [51], exhibit strong habitat dependences. In agreement with this view, Powell and Powell [52] reported that male Euglossine bees, known as mobile pollinators [53], failed to cross $100 \mathrm{~m}$ wide cleared areas. This was likely because altered microclimatic conditions constrained species movements and local species distributions [52]. For moth species, temperature is assumed to be the most important abiotic determinant of species turnover in montane rain forests [54]. Because our study was conducted at the end of the wet season, lower frequencies of rainfall during the dry season likely result in stronger differences in humidity and temperature between forest and firedegraded habitats in the dry than in the wet season. The strong differences in microclimatic conditions between forest habitats and adjacent fire-degraded habitats are a likely explanation for the observed species turn-over in our study system. Opposite responses of bee and Lepidoptera communities to altered microclimatic conditions are thus a plausible explanation for their divergent diversity patterns.

Another factor that could affect differences in pollinator communities between habitats is flower availability [38]. In our study system, flower abundances were, however, similarly high in all habitat types (mean number of flowers per $100 \mathrm{~m}^{2}: 1,100$ flowers; habitat differences: $\mathrm{F}=0.41, p=0.671$ ) [55]. In addition to resource quantities, future studies should test whether changes in resource qualities, i.e., floral traits, from forest interior to degraded habitats are associated with the species turn-over in pollinator communities, particularly with the observed opposite trends in bee and Lepidoptera communities.

\subsection{Changes in Body Size}

We could show that even on a small spatial scale bees and butterfly/moth communities varied in species' body sizes. As bee body size determines the thoracic temperature necessary for initiating flight [20], large-bodied bee species start foraging earlier during the day and in cooler conditions than 
small-bodied bee species [21]. Small-bodied species, on the other hand, can tolerate higher temperatures without overheating [21]. As temperatures were found to rise twice as high in firedegraded habitats than in forest interior habitats [D. Lippok and S. Gallegos Ayala, unpublished data], we expected to collect smaller bee species in open fire-degraded habitats. Because we actually found more large-bodied species in fire-degraded habitats than in forest interiors, we suppose that other factors drive the increase in bee body size with human disturbance in the study area. For instance, colonization ability was reported as positively correlated with bee body size [56], possibly because body size is linked to bee foraging ranges [57]. Therefore, large-bodied species could be less affected by disturbance and habitat loss than small-bodied species [58].

In contrast to bees, body sizes of butterfly/moth species decreased in degraded habitats. This could be related to the fact that body temperatures of large butterfly species are close to ambient temperatures [58] and thus need to heat up less in closed forest habitats. Schulze et al. [22] also pointed out that the forest understorey offers higher structural diversity and thus better protection against predators than open habitats. Because large-bodied butterflies move more slowly and are therefore easier to catch than small-bodied species [59], it is plausible that large-bodied butterflies are mostly found in the forest interior where they are better protected against predators.

We highlight that different pollinator guilds responded differently to the human-induced habitat gradient in our study area and that physiological differences between the studied pollinator guilds may translate into opposing trends in pollinator traits. It might be an interesting field of future research to test whether different selection pressures on different pollinator guilds result in diverging community structures also at larger spatial scales.

\section{Conclusions}

Despite the limited sampling effort of our rapid diversity assessment, we were able to demonstrate that fire-degradation of tropical montane forest has severe impacts on animal pollinator communities. Predicted future increases in fire frequencies [3] are likely to cause further decreases in abundance and richness of forest-adapted pollinator guilds, such as butterflies and moths. Because we found that bee pollinators followed an opposite pattern than butterfly and moth species, pollination services to insectpollinated plant species could be buffered by bee pollinators in fire-degraded habitats. However, the ultimate consequences of these profound changes in pollinator communities on animal-mediated pollination and plant reproductive success remain to be investigated. Our tentative findings suggest that plant species relying on generalized pollinators, such as $A$. mellifera, may suffer less from fire degradation, whereas highly specialized plant species are likely to lose crucial pollinator species in fire-degraded habitats. We conclude that changes in pollinator communities in fire-degraded habitats may be an important filter for the natural regeneration of forest plant species in the tropical Andes and elsewhere.

\section{Acknowledgements}

We thank Denis Lippok and Silvia Gallegos Ayala for their support during field work and identification of specimen. We also thank the staff of the Herbario nacional de Bolivia, La Paz. This research was funded by the Deutsche Forschungsgemeinschaft (DFG-project HE3041 /20-1). M.S. was 
also supported by the research funding program Landes-Offensive zur Entwicklung Wissenschaftlichökonomischer Exzellenz (LOEWE) of Hesse's Ministry of Higher Education, Research, and the Arts.

\section{References}

1. Barthlott, W.; Lauer, W.; Placke, A. Global Distribution of Species Diversity in Vascular Plants: Towards A World Map Of Phytodiversity (Globale Verteilung der Artenvielfalt Höherer Pflanzen: Vorarbeiten zu einer Weltkarte der Phytodiversität). Erdkunde 1996, 50, 317-327.

2. Mittermeier, R.A.; Myers, N.; Thomsen, J.B.; da Fonseca, G.A.; Olivieri, S. Biodiversity hotspots and major tropical wilderness areas: Approaches to setting conservation priorities. Conserv. Biol. 1998, 12, 516-520.

3. IPCC. Summary for Policymakers. In Climate Change 2007: Impacts, Adaptation and Vulnerability. Contribution of Working Group II to the Fourth Assessment Report of the Intergovernmental Panel on Climate Change; Parry, M.L., Canziani, O.F., Palutikof, J.P., van der Linden, P.J., Hanson, C.E., Eds.; Cambridge University Press: Cambridge, UK, 2007.

4. Webster, B.D.; Steeves, T.A. Morphogenesis in Pteridium aquilinum (L.) Kuhn-General morphology and growth habit. Phytomorphology 1958, 8, 30-41.

5. Hartig, K.; Beck, E. The bracken fern (Pteridium arachnoideum (Kaulf.) Maxon) Dilemma in the Andes of southern Ecuador. Ecotropica 2003, 9, 3-13.

6. Silva Matos, D.M.; Belinato, T.A. Interference of Pteridium arachnoideum (Kaulf.) Maxon. (Dennstaedtiaceae) on the establishment of rainforest trees. Braz. J. Biol. 2010, 70, 311-316.

7. Rodrigues, R.R.; Martins, S.V. High Diversity Forest Restoration in Degraded Areas: Methods and Projects In Brazil; Nova Publishers: São Paulo, Brazil, 2007.

8. Bawa, K.S. Plant-pollinator interactions in tropical rain forests. Annu. Rev. Ecol. Syst. 1990, 21, 399-422.

9. Schemske, D.W.; Mittelbach, G.G.; Cornell, H.V.; Sobel, J.M.; Roy, K. Is there a latitudinal gradient in the importance of biotic interactions? Annu. Rev. Ecol. Evol. Syst. 2009, 40, 245-269.

10. Knight, T.M.; Steets, J.A.; Vamosi, J.C.; Mazer, S.J.; Burd, M.; Campbell, D.R.; Dudash, M.R.; Johnston, M.O.; Mitchell, R.J.; Ashman, T.L. Pollen limitation of plant reproduction: Pattern and process. Annu. Rev. Ecol. Evol. Syst. 2005, 36, 467-497.

11. Hagen, M.; Kraemer, M. Agricultural surroundings support flower-visitor networks in an afrotropical rain forest. Biol. Conserv. 2010, 143, 1654-1663.

12. Winfree, R.; Griswold, T.; Kremen, C. Effect of human disturbance on bee communities in a forested ecosystem. Conserv. Biol. 2007, 21, 213-223.

13. Aguilar, R.; Ashworth, L.; Galetto, L.; Aizen, M.A. Plant reproductive susceptibility to habitat fragmentation: Review and synthesis through a meta-analysis. Ecol. Lett. 2006, 9, 968-980.

14. Steffan-Dewenter, I.; Münzenberg, U.; Bürger, C.; Thies, C.; Tscharntke, T. Scale-dependent effects of landscape context on three pollinator guilds. Ecology 2002, 83, 1421-1432.

15. Hamer, K.C.; Hill, J.K. Scale-dependent effects of habitat disturbance on species richness in tropical forests. Conserv. Biol. 2000, 14, 1435-1440.

16. Quesada, M.; Sanchez-Azofeifa, G.A.; Alvarez-Añorve, M.; Stoner, K.E.; Avila-Cabadilla, L.; Calvo-Alvarado, J.; Castillo, A.; Espírito-Santo, M.M.; Fagundes, M.; Fernandes, G.W.; et al. 
Succession and management of tropical dry forests in the Americas: Review and new perspectives. Forest Ecol. Manag. 2009, 258, 1014-1024.

17. Heithaus, E.R. Community structure of neotropical flower visiting bees and wasps: Diversity and phenology. Ecology 1979, 60, 190-202.

18. Potts, S.G.; Vulliamy, B.; Dafni, A.; Ne'eman, G.; Willmer, P. Linking bees and flowers: How do floral communities structure pollinator communities? Ecology 2003, 84, 2628-2642.

19. Breitbach, N.; Tillmann, S.; Schleuning, M.; Grünewald, C.; Laube, I.; Steffan-Dewenter, I.; Böhning-Gaese, K. Influence of habitat complexity and landscape configuration on pollination and seed-dispersal interactions of wild cherry trees. Oecologia 2012, 168, 425-437.

20. Bishop, J.A.; Armbruster, W.S. Thermoregulatory abilities of Alaskan bees: Effects of size, phylogeny and ecology. Funct. Ecol. 1999, 13, 711-724.

21. Pereboom, J.J.M.; Biesmeijer, J.C. Thermal constraints for stingless bee foragers: The importance of body size and coloration. Oecologia 2003, 137, 42-50.

22. Schulze, C.H.; Linsenmair, K.E.; Fiedler, K. Understorey versus canopy: Patterns of vertical stratification and diversity among Lepidoptera in a Bornean rain forest. Plant. Ecol. 2001, 153, $133-152$.

23. Hill, J.K.; Hamer, K.C.; Tangah, J.; Dawood, M. Ecology of tropical butterflies in rainforest gaps. Oecologia 2001, 128, 294-302.

24. Handel, S.N. The role of plant-animal mutualisms in the design and restoration of natural communities. In Restoration Ecology and Sustainable Development; Urbanska, K.M., Webb, N.R., Edwards, P.J., Eds.; Cambridge University Press: Cambridge, UK, 1997; pp. 111-132.

25. Dixon, K.W. Pollination and restoration. Science 2009, 325, 571-573.

26. Molina Carpio, J. Régimen de precipitación en la cuenca de Huarinilla-Cotapata, La Paz-Bolivia. Ecol. Boliv. 2005, 40, 43-55.

27. Toler, T.R.; Evans, E.W.; Tepedino, V.J. Pan-trapping for bees (Hymenoptera: Apiformes) in Utah's west desert: The importance of color diversity. Pan-Pac. Entomol. 2005, 81, 103-113.

28. Roulston, T.H.; Smith, S.A.; Brewster, A.L. A Comparison of pan trap and intensive net sampling techniques for documenting a bee (Hymenoptera: Apiformes) fauna. J. Kansas Entomol. Soc. 2007, 80, 179-181.

29. Schleuning, M.; Farwig, N.; Peters, M.K.; Bergsdorf, T.; Bleher, B.; Brandl, R.; Dalitz, H.; Fischer, G.; Freund, W.; Gikungu, M.W. Forest fragmentation and selective logging have inconsistent effects on multiple animal-mediated ecosystem processes in a tropical forest. PloS One 2011, 6, e27785.

30. Campbell, J.W.; Hanula, J.L. Efficiency of malaise traps and colored pan traps for collecting flower visiting insects from three forested ecosystems. J. Insect Cons. 2007, 11, 399-408.

31. R Development Core Team. $R$ : A Language and Environment for Statistical Computing; R Foundation for Statistical Computing: Vienna, Austria, 2008.

32. Oksanen, J.; Blanchet, F.G.; Kindt, R.; Legendre, P.; Minchin, P.R.; O’Hara, R.B.; Simpson, G.L.; Solymos, P.; Stevens, M.H.H.; Wagner, H. Vegan: Community ecology package, 2011; R package version 2.0-1. 
33. Pinheiro, J.; Bates, D.; DebRoy, S.; Sarkar, D. The R development core team (2011) nlme: Linear and nonlinear mixed effects models, 2011; R package version 3.1-106.

34. Dray, S.; Dufour, A.B. The Ade4 package: Implementing the duality diagram for ecologists. $J$. Stat. Softw. 2007, 22, 1-20.

35. Ewers, R.M.; Didham, R.K. Confounding factors in the detection of species responses to habitat fragmentation. Biol. Rev. 2006, 81, 117-142.

36. Legendre, P.; Galzin, R.; Harmelin-Vivien, M.L. Relating behaviour to habitat: Solutions to the fourth-corner problem. Ecology 1997, 78, 547-562.

37. Dray, S.; Legendre, P. Testing the species traits-environment relationships: The fourth-corner problem revisited. Ecology 2008, 89, 3400-3412.

38. Otero, J.T.; Sandino, J.C. Capture rates of male Euglossine bees across a human intervention gradient, Chocó region, Colombia. Biotropica 2006, 35, 520-529.

39. Liow, L.H.; Sodhi, N.S.; Elmqvist, T. Bee diversity along a disturbance gradient in tropical lowland forests of south-east Asia. J. Appl. Ecol. 2001, 38, 180-192.

40. Tonhasca, A., Jr.; Blackmer, J.L.; Albuquerque, G.S. Abundance and diversity of Euglossine bees in the fragmented landscape of the Brazilian Atlantic forest. Biotropica 2002, 34, 416-422.

41. Zayed, A.; Whitfield, C.W. A genome-wide signature of positive selection in ancient and recent invasive expansions of the honey bee Apis mellifera. Proc. Natl. Acad. Sci. USA 2008, 105, 3421-3426.

42. Brosi, B.J.; Daily, G.C.; Ehrlich, P.R. Bee community shifts with landscape context in a tropical countryside. Ecol. Appl. 2007, 17, 418-430.

43. Brosi, B.J.; Daily, G.C.; Shih, T.M.; Oviedo, F.; Durán, G. The effects of forest fragmentation on bee communities in tropical countryside. J. Appl. Ecol. 2008, 45, 773-783.

44. Wilms, W.; Wiechers, B. Floral resource partitioning between native Melipona bees and the introduced Africanized honey bee in the Brazilian Atlantic rain forest. Apidologie 1997, 28, 339-355.

45. Stefanescu, C.; Herrando, S.; Páramo, F. Butterfly species richness in the north-west Mediterranean basin: The role of natural and human-induced factors. J. Biogeogr. 2004, 31, 905-915.

46. Hill, J.K.; Hamer, K.C.; Lace, L.A.; Banham, W.M.T. Effects of selective logging on tropical forest butterflies on Buru, Indonesia. J. Appl. Ecol. 1995, 32, 754-760.

47. Kitahara, M.; Fujii, K. Biodiversity and community structure of temperate butterfly species within a gradient of human disturbance: An analysis based on the concept of generalist vs. specialist strategies. Res. Popul. Ecol. 1994, 36, 187-199.

48. Hogsden, K.L.; Hutchinson, T.C. Butterfly assemblages along a human disturbance gradient in Ontario, Canada. Can. J. Zoolog. 2004, 82, 739-748.

49. Potts, S.G.; Dafni, A.; Ne'eman, G. Pollination of a core flowering shrub species in Mediterranean phrygana: variation in pollinator diversity, abundance and effectiveness in response to fire. Oikos 2003, 92, 71-80.

50. Tylianakis, J.M.; Klein, A.-M.; Tscharntke, T. Spatiotemporal variation in the diversity of Hymenoptera across a tropical habitat gradient. Ecology 2005, 86, 3296-3302.

51. Bawa, K.S.; Bullock, S.H.; Perry, D.R.; Coville, R.E.; Grayum, M.H. Reproductive biology of tropical lowland rain forest trees. II. Pollination systems. Am. J. Bot. 1985, 72, 346-356. 
52. Powell, A.H.; Powell, G.V. Population dynamics of male Euglossine bees in Amazonian forest fragments. Biotropica 1987, 19, 176-179.

53. Janzen, D.H. Euglossine Bees as long-distance pollinators of tropical plants. Science 1971, 171, 203.

54. Brehm, G.; Homeier, J.; Fiedler, K. Beta diversity of Geometrid moths (Lepidoptera: Geometridae) in an Andean montane rainforest. Divers. Distrib. 2003, 9, 351-366.

55. Kambach, S. Differences in diversity and composition of pollinator guilds between montane forest and arrested succession in Bolivia. Diploma Thesis, University of Halle-Wittenberg, 2012.

56. Gathmann, A.; Greiler, H.-J.; Tscharntke, T. Trap-nesting bees and wasps colonizing set-aside fields: Succession and body size, Management by cutting and sowing. Oecologia 1994, 98, 8-14.

57. Greenleaf, S.S.; Williams, N.M.; Winfree, R.; Kremen, C. Bee foraging ranges and their relationship to body size. Oecologia 2007, 153, 589-596.

58. Bommarco, R.; Biesmeijer, J.C.; Meyer, B.; Potts, S.G.; Pöyry, J.; Roberts, S.P.M.; Steffan-Dewenter, I.; Öckinger, E. Dispersal capacity and diet breadth modify the response of wild bees to habitat loss. P. Roy. Soc. B-Biol. Sci. 2010, 277, 2075-2082.

59. Thomas, C.D.; Hill, J.K.; Lewis, O.T. Evolutionary consequences of habitat fragmentation in a localized butterfly. J. Anim. Ecol. 1998, 67, 485-497.

(C) 2012 by the authors; licensee MDPI, Basel, Switzerland. This article is an open access article distributed under the terms and conditions of the Creative Commons Attribution license (http://creativecommons.org/licenses/by/3.0/). 